\title{
Comunicação e entretenimento na cibercultura: repensando as articulações entre lúdico, cognição e tecnologia
}

\section{Fátima Regis e Letícia Perani}

\section{Resumo}

As TIC têm promovido uma verdadeira revolução nos sistemas de mídia e entretenimento contemporâneos. Essa mudança potencializa práticas socioculturais - participação, sociabilização e aprendizado de linguagens - que exigem do usuário o refinamento de habilidades cognitivas. 0 objetivo do texto é mostrar como a cibercultura, ao evidenciar as atividades cognitivas presentes nas práticas de comunicação e entretenimento, provoca um duplo reposicionamento: tanto os termos jogo/entretenimento, quanto os termos tecnologia/mídia são associados à cognição. Tomaremos como base a mudança do conceito de cognição no século XX para repensar as articulações entre tecnologia, ludicidade e cognição na cibercultura. Como resultados preliminares, verifica-se que 0 entretenimento deixa de ser infantil, não-sério e escapista, aproximando-se da categoria de lúdico, e que a tecnologia deixa de ser mera ferramenta para tornarse agente nos processos cognitivos.

\section{Palavras-chave:}

Tecnologias de Informação e Comunicação. Cibercultura. Entretenimento. Cognição.

Fátima Régis I fatimaregisoliveira@gmail.com Doutora em Comunicação e Cultura pela Universidade Federal do Rio de Janeiro -UFRJ. Professora do Programa de Pós-Graduação em Comunicação da Universidade do Estado do Rio de Janeiro - UERJ.

Letícia Perani I leticiaperani@yahoo.com.br

Mestre em Comunicação pela UERJ. Pesquisadora de Comunicação e Cibercultura, com ênfase em games e entretenimento.

\section{Introdução}

A mente humana parece tirar mais vantagem dos jogos do que em buscas mais sérias

Leibniz

0 advento das Tecnologias de Informação

e de Comunicação (TIC) tem promovido uma verdadeira revolução na indústria do entretenimento. Diversos pesquisadores destacam que os sistemas de mídia e 0 entretenimento contemporâneo estão mais complexos e demandam do usuário o desenvolvimento de práticas participação, sociabilização e aprendizado de linguagens e interfaces - que requerem um refinamento de habilidades cognitivas.

Ao evidenciar as atividades cognitivas presentes nas práticas culturais contemporâneas, a cibercultura parece produzir um reposicionamento das concepções de entretenimento e tecnologia. 0 entretenimento parece não se restringir aos seus predicados usuais de infantil, não-sério e escapista, aproximando-se assim da categoria de lúdico. Por sua vez, a tecnologia/mídia deixa de ser mera 
ferramenta, prótese ou extensão para tornar-se agente nos processos cognitivos.

A proposta deste texto é tomar como base a mudança no conceito de cognição no século $\mathrm{XX}$ para realizar seu objetivo: repensar as articulações entre tecnologia, ludicidade e cognição nos processos da cibercultura. 0 corpo do artigo está subdividido em três partes. A primeira consiste em um breve mapeamento das habilidades cognitivas atribuídas, pelos teóricos da cibercultura, às práticas de comunicação e entretenimento atuais. Em seguida, apresentamos algumas acepções do conceito de lúdico como forma de repensar a ideia de entretenimento. Como veremos, a acepção mais geral de entretenimento não confere ao termo os atributos cognitivos descritos pelos autores pesquisados. Tais características descrevem melhor a noção daquilo que, ao longo da história, foi denominado lúdico. Na terceira parte, considerando que a mídia e o entretenimento hoje são associados a competências que requerem um refinamento cognitivo em diversas áreas, faremos uma breve discussão sobre o conceito de cognição, evidenciando que hoje os processos cognitivos são indissociáveis de sua articulação com ambiente, objetos técnicos e interações sociais.

\section{Habilidades cognitivas no entretenimento e nas práticas de comunicação da Cibercultura}

Apesar de pesquisadores como Georg Simmel (1987) e Walter Benjamin (1994) terem argumentado sobre os modos como as tecnologias de comunicação da metrópole moderna reconfiguraram as percepções e experiências subjetivas dos indivíduos, no século XX prevaleceram as teorias sobre a produção de sentido e conteúdos estéticos e ideológicos nos meios de comunicação de massa (MCM). Ao analisar os produtos de entretenimento sob as lentes da estética, da representação e da ideologia, diversas teorias (Escola de Frankfurt, Estruturalismo, Imperialismo Cultural e outras) classificaram o entretenimento de massa como culturalmente inferior, alienante e de baixo padrão estético e cognitivo.

Na virada do século XXI, o advento das TIC tem sido um forte aliado na mudança deste panorama. Com o surgimento da Internet e a reconfiguração das mídias anteriores, inaugurase uma verdadeira revolução nas práticas culturais contemporâneas.

Destacamos três processos da cibercultura imprescindíveis para esta revolução. 0 primeiro - digitalização - permitiu a transposição de códigos e linguagens provenientes dos diversos tipos de meios (analógicos e digitais) para a base digital, favorecendo as práticas de recombinações de textos, ilustrações, fotos, sons, músicas, animações e vídeos. A integração de mídias, decorrente do surgimento de equipamentos e tecnologias compatíveis entre si (Ipods, Iphones, Palm Tops, Celulares), favoreceu o amplo fluxo de circulação de conteúdos. 0 terceiro processo 
- redes - possibilitou a produção, troca e

compartilhamento de produtos e informações, incrementando o surgimento de redes sociais, comunidades virtuais, sites de relacionamento, entre outros. 0 fato é que a articulação conjunta desses três processos deflagrou práticas culturais que demandam de seus usuários uma "atuação mais ativa", estimulando assim o refinamento de competências cognitivas por parte do usuário.

Se os teóricos da comunicação massiva, de um modo geral, desqualificavam os atributos estéticos e cognitivos da comunicação tradicional, algo diferente parece ocorrer no sistema de mídias atual: diversos estudiosos da cibercultura (LEMOS, 2002; SANTAELLA, 2003; 2004; SÁ, 2004; 2006; JOHNSON, 2005; ANDERSON, 2006; GEE, 2007; FELINTO, 2008; JENKINS, 2008, entre outros) ressaltam as características e habilidades cognitivas estimuladas pelas tecnologias digitais e produtos de entretenimento contemporâneo.

A partir de uma pesquisa exploratória e preliminar, parece-nos possível apontar três práticas sociais instigadas pelas TIC que permitem essa revolução na cultura popular: participação do usuário; aprendizagem de linguagens, interfaces e softwares; e interações sociais.

Destacamos abaixo alguns breves excertos de textos de teóricos da cibercultura que nos permitem sintetizar as três práticas. A primeira - participação do usuário - sub-divide-se em três modos.

\subsection{Participação do usuário}

\subsubsection{Busca da informação desejada}

A pesquisadora brasileira Lúcia Santaella afirma:

Os novos processos comunicativos constituídos pela introdução de novas tecnologias e 0 dialogismo entre elas e as anteriores nos arrancaram da inércia da recepção de mensagens impostas de fora e nos treinaram para a busca de informação e do entretenimento que desejamos encontrar (2003, p. 16, grifos nossos).

0 teórico Henry Jenkins argumenta:

A convergência [das mídias] representa uma transformação cultural, à medida que os consumidores são incentivados a procurar novas informações e fazer conexões em meio a conteúdos midiáticos dispersos. Este livro é sobre 0 trabalho - e as brincadeiras - que os espectadores realizam no novo sistema de mídia (2008, p. 28, grifos nossos).

Por exemplo, a experiência de acompanhar uma série de TV hoje não se limita a assistir aos episódios exibidos semanalmente. Os fãs de seriados como Lost, Heroes e 24 Horas, precisam buscar informações adicionais sobre os personagens e discutir teorias sobre as sub-tramas em diversos fóruns como: listas de discussão, comunidades virtuais, redes sociais, blogs e websites.

\subsubsection{Produtor/criador de conteúdo}

Chris Anderson, em seu já clássico A Cauda Longa, pondera: "A consequência de tudo isso [tecnologia, barata e onipresente] é que estamos deixando de ser apenas consumidores passivos 
para passar a atuar como produtores ativos" (2006, p. 61). Mais adiante aponta que "[a internet] favorece a criação de novos modelos de "arte", como os mashups (tocar a faixa de um artista sobre outra) e os spoofs (criações sobre vídeos) pelo usuário comum (Idem, grifos nossos).

A esse processo em que a participação do usuário se dá por meio de criações e recombinações de linguagens e mídias, Lev Manovich denomina remixabilidade:

0 processo transformativo por meio do qual os meios e as informações que organizamos e compartilhamos podem ser recombinados e construídos de modo a criar novas formas, conceitos, ideias, mashups e serviços (MANOVICH, 2005, tradução nossa).

Como exemplo desse processo, podemos citar o diretor de cinema Esmir Filho, cujo talento foi descoberto a partir de seu curta " 0 Tapa na Pantera", que virou um fenômeno de visualizações pelo YouTube (PORTO, 2006), desencadeando assim sua carreira profissional.

\subsubsection{Exploração de ambientes}

Os estudiosos de games, Espen Aarseth e Steven Johnson destacam que a participação do usuário se dá também por meio da exploração de ambientes.

0 norueguês Espen Aarseth defende que os videogames são um tipo de texto que demanda do "usuário" um trabalho físico, corporal, um esforço não-trivial, distinto do esforço de interpretar um texto no ato da leitura tradicional. A esses textos que demandam um desempenho corporal por parte do "leitor", Aarseth denomina de cibertextos. Para Aarseth, "o leitor do cibertexto é um jogador; [...]; ele pode explorar, perder-se e descobrir caminhos secretos nesses textos [...]" $(1997$, p. 4)

Steven Johnson vai além e argumenta que o desejo de explorar é uma característica neurológica dos humanos, associada à sensação de prazer. "No que diz respeito à ligação de nosso cérebro, 0 instinto de desejo desencadeia o desejo de explorar" (JOHNSON, 2005, p. 29, grifos nossos); ou seja, a utilização de um sistema de recompensas nos jogos e ambientes eletrônicos em geral estaria ligada a este instinto para a busca de desejos/prazeres, que instiga a exploração de espaços e objetos.

Como exemplo, em outro artigo (REGIS; PERANI, 2010), no qual efetuamos pesquisa empírica em games da série Sim (produzidos pela norteamericana Electronic Arts), pudemos notar que todos os jogos pesquisados incentivam a exploração desses ambientes virtuais; em especial, verificamos que os games mais novos, como Spore (2008), exigem um refinamento maior nas competências de associação, de sondagem e de conhecimento de novos objetivos e regras no decorrer do jogo.

\subsection{Aprendizagem de linguagens, interfaces e softwares}

Steven Johnson pondera que o e-mail e a Web nos capacitaram para: 
[...] aprender toda uma nova linguagem de comunicação e um pequeno arsenal de ferramentas de software junto com ela. (2005, p. 92).

James Paul Gee caracteriza os videogames como domínios semióticos que exigem a capacidade de apreensão de diversos tipos de linguagens verbais e não-verbais. Em suas palavras, videogames são

[...] conjuntos de práticas que envolvem uma ou mais modalidades (por exemplo, linguagem oral ou escrita, imagens, equações, símbolos, gestos sonoros, gráficos, artefatos etc.) para comunicar tipos de significados peculiares (GEE, 2007, p. 19, tradução nossa).

Esta aprendizagem é facilmente exemplificada pelos modelos de aprendizagem dos jogos do console Wii, lançado pela fabricante Nintendo em 2006.

Como Wii exige dos jogadores algumas modificações no modo habitual de se jogar, demandando uma participação corpórea maior, uma grande parte dos games lançados para esta plataforma costuma ter uma fase inicial de treino e aprendizagem, na qual as regras e teclas de comando são minuciosamente explicadas e adestradas; sem essa aprendizagem, 0 poder de ação do jogador sobre o jogo se torna muito limitado.

\subsection{Interações sociais}

Em relação ao incentivo às interações sociais, Henry Jenkins defende:
A convergência ocorre dentro dos cérebros de consumidores individuais e em suas interações sociais com outros. [...] Nenhum de nós pode saber tudo; cada um de nós sabe alguma coisa; e podemos juntar as peças, se associarmos nossos recursos e unirmos nossas habilidades (2008, p. 28).

Sobre o mesmo tema, Chris Anderson assevera:

A internet se tornou 0 veículo favorito para escutar música. E o que aconteceu com a música aconteceu com todos os setores de mídia e de entretenimento de massa: as pessoas querem produtos de nicho. Querem formar grupos por afinidades e interesses comuns (2006, p. 12).

0 que pretendemos destacar com esses excertos é que, para sua realização, as práticas citadas acima estimulam o desenvolvimento de um amplo repertório cognitivo, envolvendo habilidades sensoriais, perceptivas e sociais, além das atividades de inteligência tradicional, tais como lógica, resolução de problemas, análise, reconhecimento de padrões e tomada de decisão. Assim, os produtos de entretenimento atuais parecem demandar a ação do corpo e de formas cognitivas, irredutíveis às habilidades representacionais pelas quais costumamos julgar a cultura de massa ${ }^{1}$. Ao incluir atividades pertencentes a um amplo repertório cognitivo ${ }^{2}$, como as de exploração de ambientes, aprendizagem de linguagens e interações sociais,

Para um aprofundamento das relações entre as práticas da cibercultura e as habilidades cognitivas envolvidas, ver Regis (2008)

Pioneiro dos estudos sobre a cibercultura, Pierre Lévy (1993) já pregava a vocação das TIC para o desenvolvimento da sociabilização e da construção do que denominou de "inteligência coletiva". Na acepção de Lévy, porém, as tecnologias da inteligência são atributos exclusivos da comunicação mediada por computador (multilateral e democrática). Para 0 autor, esta é uma diferença crucial das TIC com os MCM (comunicação unilateral e autoritária). Em nossa pesquisa consideramos que todo o sistema de mídias (tradicionais e atuais, analógicas e digitais) tem potencial cognitivo. 
as práticas de comunicação e entretenimento contemporâneo se remetem ao termo lúdico que discutiremos a seguir.

\section{Ampliando a noção de entretenimento: 0 lúdico}

Nos tempos hodiernos, associar os termos lúdico e entretenimento parece uma ação comum, até mesmo involuntária: os dois vocábulos seriam sinônimos, que representariam a vontade humana de passar o tempo com uma atividade agradável e diferente das suas tarefas cotidianas. Essa concepção do lúdico como divertimento é adotada por diversos teóricos da comunicação, especialmente após o surgimento dos jogos eletrônicos que explicitaram essa ligação de forma marcante e inequívoca.

Porém, 0 interesse de diversas disciplinas (Filosofia, Antropologia, Pedagogia, Psicologia, Educação Física e, recentemente, as Ciências da Comunicação) sobre o termo lúdico produziu abordagens plurais e até incompatíveis entre si. Construído a partir de interconexões entre diversas ciências ao longo dos séculos, o lúdico tornou-se um vocábulo aberto, polissêmico e muitas vezes ambíguo.

Mas, se à primeira vista a ambiguidade do termo parece conferir ao lúdico uma imprecisão conceitual, um olhar mais atento focaliza suas conexões precisas. Em verdade, a associação do lúdico exclusivamente a entretenimento, além de limitar o termo, reflete a permanência de uma noção central ao longo de séculos: a oposição entre jogo e seriedade, fundada por Aristóteles. Para o filósofo de Estagira, que delineou esse pensamento por meio de ilações sobre as concepções de prazer dos filósofos présocráticos e de Platão, os jogos possuem apenas um caráter recreativo, sem as articulações com os campos do sagrado e/ou das competições que eram utilizadas pela cultura helênica clássica. Na filosofia aristotélica a felicidade é 0 bem supremo, por ser auto-suficiente e realizada, não possuindo nenhuma outra finalidade a não ser ela mesma. Aristóteles se detém em provar que o jogo não compartilha desses atributos. A felicidade não estaria na recreação, já que esta é realizada para a boa continuidade do trabalho e dos atos virtuosos, sendo por isso uma atividade meio e não finalidade. Em Política, encontramos uma passagem que explicita as ideias de Aristóteles sobre a função do jogo:

Se o repouso e o trabalho são ambos indispensáveis, o repouso é pelo menos preferível, e é uma questão importante saber em que se deve empregar o lazer. Certamente não no jogo; senão, o jogo seria o nosso fim último. Se possível, é melhor descartar 0 jogo entre as ocupações. Quem trabalha precisa de descanso: 0 jogo não foi imaginado senão para isto. 0 trabalho é acompanhado de fadiga e de esforços. É preciso entremeá-lo convenientemente de recreações, como um remédio (ARISTÓTELES, [344 a.c.?] , p. 57).

Ver as atividades lúdicas como dispensáveis, infantis ou até mesmo danosas para o indivíduo e para a sociedade é uma herança direta da 
filosofia de Aristóteles, e esta acepção se tornou tão arraigada no pensamento ocidental que apenas no século XIX, a partir do Romantismo, foi contestada com mais vigor. No decorrer dos séculos, foram feitas várias colaborações ao conceito. 0 Império Romano deu um novo significado ao jogo, ao acrescentar os sentidos de treinamento, simulacro e exercício. 0 termo latino ludus, que originou a palavra portuguesa lúdico, era também sinônimo de escola, pois o jogo era usado para a aprendizagem de atividades "reais", como as simulações de guerra (BROUGÈRE, 1998). Entre os pensadores medievais, foi São Tomás de Aquino quem desenvolveu os estudos mais relevantes sobre a importância dos jogos. Aquino abordou as atividades lúdicas sob um ponto de vista ético e antropológico, abrangendo o papel dos jogos na sociedade, a necessidade das brincadeiras, suas virtudes e vícios. É o jogo dos adultos que é debatido e tratado pelo filósofo católico como uma virtude moral imprescindível ao convívio social (LAUAND, 2000).

Do século XVI até o século XVIII, os jogos de azar transformaram-se no modelo de atividade lúdica, como é demonstrado nas enciclopédias da época (DUFLO, 1999; BROUGÈRE, 1998). Nesse momento, as atividades lúdicas vão adquirir duas funções dicotômicas. Se, por um lado, os jogos de azar podem cultivar o vício, destruindo famílias e a dignidade humana (DUFLO, 1999; BROUGÈRE, 1998); por outro, tornam-se objeto de estudo de pesquisadores ávidos por desvendar os mistérios do acaso. A Matemática se encarrega de analisar as atividades lúdicas, pensadas como fenômenos originados por meio da engenhosidade humana, merecendo, por isso, estudos aprofundados (DUFLO, 1999). Para os matemáticos,

[...] 0 jogo deve ser estudado porque oferece um espaço privilegiado no qual se exerce a inteligência humana, por duas razões diferentes e complementares. Por um lado, há o prazer, que é um incentivo formidável [...] Por outro lado e sobretudo, no jogo, 0 espírito se exerce livremente, sem 0 constrangimento da necessidade e do real, oferece condições puras de exercício da engenhosidade (DUFL0, 1999, p. 25).

0 filósofo G. W. Leibniz registrou o início dos estudos matemáticos sobre o lúdico, em seu livro Novos ensaios sobre o entendimento humano, publicado em 1703. Após descrever o início das explorações lógicas nos jogos de azar, Leibniz argumentou sobre a necessidade de outros estudos de Lógica que abordassem as probabilidades para complementar a Lógica fundada por Aristóteles. Para Leibniz, o jogo impõe uma vigília do pensamento, pois envolve riscos e combinações necessárias, "ensinando" ao jogador o exercício do raciocínio; o lúdico envolve prazeres que levam o indivíduo a fazer cálculos que ele não faria em outras circunstâncias (DUFL0, 1999).

Já os estudiosos da Pedagogia do século XVIII, denominados pré-românticos, trouxeram a ideia de que o jogo faz parte da natureza da criança, uma qualidade que deve ser utilizada para que o educador obtenha um maior sucesso 
em sua missão ${ }^{3}$. Dentre esses pensadores, podemos citar Jean-Jacques Rousseau, que se debruçou sobre essa questão em Emílio ou Da Educação, publicado originalmente em 1762. 0 filósofo francês acreditava que 0 jogo faz parte da natureza da criança, que deve ser preservada para que se descubram as suas verdadeiras necessidades: "a natureza provê, do seu próprio jeito, o que é necessário para 0 crescimento da criança, e isso nunca deve ser contrariado [...] Todas as suas atividades próprias são instintos do corpo para 0 seu crescimento vigoroso" (ROUSSEAU, 2004, tradução nossa). Essa visão de Rousseau, apesar de valorizar o lúdico como uma interessante ferramenta para o desenvolvimento humano, reforçou a concepção dos jogos como atividades frívolas, voltadas apenas para a diversão. Foi, porém, com 0 apreço pela figura simbólica da criança pelos românticos do século XIX, que o jogo, ainda visto como atividade infantil, recebeu também uma reavaliação, conquistando definitivamente seu espaço em explorações científicas diversas e possibilitando até mesmo o surgimento de um campo do conhecimento autônomo no século XX: os game studies.

Assim, podemos notar que a visão sobre o jogo se modifica de acordo com o pensamento de cada época, trazendo novos significados e usos. 0 lúdico pode ser sinônimo de prazer, oposição ao trabalho, ferramenta da engenhosidade humana, instrumento pedagógico, simulação, esporte, brincadeira infantil, entre outros.

E através deste breve apontamento das transformações de sentido do lúdico, demonstrando as várias nuances presentes em um tema pesquisado há milhares de anos, chegamos a um significado de jogo que aliaria várias dessas características que evidenciamos anteriormente para demonstrar toda a potencialidade cognitiva desse conceito: o lúdico como experiência exploratória. Em sua acepção mais aceita, os jogos possibilitam a construção de uma experiência estética, vivenciada de forma diferente do dia-a-dia, a partir de uma "separação" espaço-temporal; separação esta que nos traz a necessidade de assimilação das regras de funcionamento desse verdadeiro universo paralelo constituído nestes domínios. Por isso, o lúdico é também ambiente de explorações e descobertas, que permitem buscar informações sobre o meio, contribuindo para inúmeras aprendizagens e para o convívio social, demonstrando que os jogos podem servir como forma de compreensão e domínio de uma dada conjuntura, habilidades que posteriormente são aproveitadas para a produção de situações distintas, diferentes das iniciais.

Este pensamento foi inspirado pela obra De pueris instituendis, de Erasmo, publicada no século XVI, que tinha como mote o fato de a criança supostamente não entender a importância do conhecimento que the é repassado, sendo as atividades lúdicas uma maneira de levá-la à realização do trabalho, sem que ela perceba. Porém, Erasmo aconselhava o cuidado com a utilização dos jogos, que devem ser apenas um paliativo para a educação, senão, futuramente, a criança pode se tornar um jogador, com toda a carga negativa que o termo possuía (DUFL0, 1999) 
Sendo uma função cognitiva para a apreensão

e a compreensão do ambiente, ou inclusive

das habilidades corpóreas, esta percepção

de affordances ${ }^{4}$ realizada através do jogo é

extremamente importante para 0 desenvolvimento

humano e a aquisição de conhecimentos e

experiências. Todas essas características podem

ser identificadas nas práticas de entretenimento

contemporâneo, por isso nossa sugestão de que 0

lúdico talvez seja uma concepção mais adequada

para analisar o sistema de mídias e as práticas

lúdicas da cibercultura.

\section{Cognição hoje: corporificação, ancoragem e sociabilidade}

Na tradição da filosofia ocidental, a cognição

é tarefa prioritária, quando não exclusiva,

dos processos mentais, frequentemente

descorporificados, relegando as experiências

sensório-motoras e as tecnologias a categorias

secundárias. Basta pensarmos em filósofos como

Platão, Descartes e Kant para ilustrar essa ideia.

Em meados do século XX, os pioneiros da

inteligência artificial (IA) mantiveram a tradição

da cognição descorporificada. Os pesquisadores

da IA clássica se dedicaram a reproduzir

automaticamente as faculdades da inteligência

humana associadas à tomada de decisões e à solução de problemas lógico-matemáticos, tais

como jogar xadrez e realizar cálculos aritméticos

complexos. A abordagem clássica fundamenta-

se na teoria computacional da mente, ou seja,

a tese de que a partir de um conjunto de regras

lógico-formais pode-se traduzir funções cognitivas

para o formato de representações simbólicas ${ }^{5}$.

Desse modo, as funções cognitivas são

determinadas exclusivamente pela lógica formal, independentemente das propriedades materiais

do sistema, o que permite a identificação

entre mente e máquina computacional, base

da teoria. Ao definir inteligência como função

de manipulação de símbolos de acordo com

regras da lógica formal, a IA clássica ignora as

habilidades relacionadas às funções sensório-

motoras e às interações do indivíduo com 0

mundo no processo cognitivo.

Na década de 80, observou-se que, se os

computadores executam com extrema facilidade

tarefas que requerem inteligência tradicional

(raciocínio lógico-matemático), há outras

atividades que 0 homem faz sem pensar -

como andar, manusear objetos e reconhecer

uma pessoa - que são extremamente difíceis

de automatizar. As ciências cognitivas e

neurociências demonstram que 0 sistema

sensório-motor ocupa a maior parte de nossos

Segundo a teoria da Perspectiva Ecológica, que tem sua origem nas Ciências Cognitivas, affordances "são exatamente as possibilidades oferecidas pelo ambiente a um agente particular..." (OLIVEIRA; RODRIGUES, 2006)

Essas representações simbólicas são a base pela qual se redige a sequência de instruções elementares - 0 algoritmo - usada para programar o computador. A programação é feita passo a passo, enfatizando o processamento top-down - quando uma representação de alto nível da tarefa é usada para iniciar, monitorar e/ou guiar as ações seguintes, detalhadamente (BODEN, 1996, p. 4) 
cérebros e é resultado de dois bilhões de anos de evolução (MORAVEC, 1988). Hans Paul Moravec estima que o processo denominado mente só é possível porque tem como suporte o saber mais antigo e mais potente dos mecanismos sensóriomotores, e argumenta: "organismos que não possuem a habilidade de perceber e explorar seus ambientes - como as plantas - não parecem adquirir capacidade de desenvolver inteligência" (1988, p. 16).

Alinhados com essas novas ideias, pesquisadores de linhas teóricas distintas (DENNETT, 1996; LAKOFF; JOHNSON, 1999; CLARK, 2001; VARELA, s/d) questionam a ausência de corpo e história nos processos cognitivos da teoria computacional da mente. Eles entendem que a mente é 0 resultado de um longo processo evolutivo que envolve as relações entre corpo e cérebro e suas interações com 0 ambiente ao longo da história biológica e cultural do indivíduo. Essas ideias inspiraram uma nova abordagem dos estudos em inteligência artificial - 0 conexionismo, que se baseia no modo de interação entre os neurônios do cérebro.

A abordagem conexionista trabalha com 0 processamento bottom-up: a ideia de que 0 comportamento de um modelo conexionista depende das interações locais das unidades individuais, nenhuma das quais possuindo uma visão total da tarefa a ser realizada - são as entradas detalhadas do sistema que determinam o passo seguinte. Para os pesquisadores dessa abordagem, os primeiros problemas a se resolver são os de percepção e mobilidade (MORAVEC, 1988, p. 17). Para pesquisar os problemas de percepção e ação, os pesquisadores associaram suas redes neurais a modelos concretos, criando os robôs situados ou ancorados. Essa nova tendência na robótica busca construir robôs mais autônomos e mais próximos dos organismos vivos. Um desses robôs é Cog. Rodney Brooks, seu criador, escolheu o nome porque evoca tanto a palavra "cognição" quanto os mecanismos dentados de uma roda. Cog foi criado com 0 objetivo de modelar a inteligência humana em um robô com corpo físico, possibilitando a investigação dos fatores que hoje definem cognição: desenvolvimento, incorporação física, integração sensório-motora e interação social (MENZEL; D'ALUISIO, 2000, p. 64).

As pesquisas com robôs ancorados provocaram uma revolução nos estudos sobre ação e percepção. Andy Clark explica que o velho esquema "perceber-pensar-agir" tornou-se anacrônico (2001, p. 88). Descobriu-se que a percepção não é um fenômeno passivo no qual a atividade motora é iniciada ao final de um processo complexo em que o indivíduo cria uma representação detalhada da cena percebida. Em vez disso, percepção e ação se articulam de modo que 0 aparelho motor começa a agir muito antes que os sinais sensoriais alcancem o nível superior (raciocínio) no processo cognitivo. Clark explica que o processamento perceptivo inicial pode gerar um tipo de protoanálise da 
cena, possibilitando que o indivíduo selecione ações (tais como movimentos da cabeça ou dos olhos) cujo papel é prover um sinal sensorial ligeiramente aperfeiçoado. Deste modo, percepção, ação e cognição atuam simultaneamente e de forma integrada. A percepção é entrelaçada com possibilidades para a ação e é continuamente influenciada por fatores sensório-motores e contextuais (CLARK, 2001, p. 95).

A abordagem conexionista da IA, a robótica, as ciências cognitivas afirmam que 0 processo cognitivo precisa de um suporte corporal aparato sensório-motor - que explora o mundo em busca de informações relevantes. Além de corporificada, a cognição não se limita às habilidades de nível superior (racionais, lógicomatemáticas). Antes, a cognição se beneficia da articulação complexa entre uma gama de habilidades, tal como explicam Lakoff e Johnson:

Nas ciências cognitivas, o termo cognitivo é usado para qualquer tipo de operação ou estrutura mental. [...] Dessa forma, o processo visual classifica-se como cognitivo, assim como 0 processo auditivo. [...] Memória e atenção classificam-se como cognitivas. Todos os aspectos do pensamento e da linguagem, conscientes ou inconscientes, são assim cognitivos. [...] Imagens mentais, emoções e a concepção de operações motoras também são estudadas sob uma perspectiva cognitiva (1999, p. 11-12, tradução nossa).

Por essa nova perspectiva, seres vivos têm suas ações acopladas ao mundo; suas decisões são contextualizadas, ancoradas em situações concretas e se apoiam em todos os nossos sentidos e habilidades. E isso não é tudo. Ao postular que conhecimento e comportamento não são resultados de representações do mundo, mas processos emergentes da dinâmica das interações concretas com o mundo, pesquisadores como Donald Norman e Andy Clark incluem no processo cognitivo as interações com outros indivíduos e com os objetos técnicos. Norman denomina de artefatos cognitivos qualquer ferramenta que auxilie a mente (1993, p. 4), o que inclui tanto artefatos materiais - como o papel, o lápis, a calculadora, o computador - quanto artefatos mentais - como a linguagem, a lógica e a aritmética. Norman destaca ainda a importância da cooperação social para as atividades cognitivas:

As pessoas operam como um tipo de inteligência distribuída, na qual grande parte de nosso comportamento inteligente resulta da interação de processos mentais com os objetos e determinações do mundo e na qual muitos comportamentos ocorrem por meio de um processo cooperativo com outrem (NORMAN, 1993, p. 146).

Andy Clark resume assim os diversos fatores que compõem a complexidade da mente humana:

$$
\begin{aligned}
& \text { A ideia central de mente, ou melhor o tipo espe- } \\
& \text { cial de mente associada com as relações de al- } \\
& \text { to-nível, distintivas da espécie humana, emerge } \\
& \text { a partir da colisão produtiva de múltiplos fatores } \\
& \text { e forças - alguns corporais, alguns neurais, al- } \\
& \text { guns tecnológicos e alguns sociais e culturais } \\
& \text { (2001, p. 141). }
\end{aligned}
$$

Para conhecer e operar no mundo, a mente conta não apenas consigo mesma, mas com 0 ambiente, os objetos técnicos e as interações sociais. 


\section{Considerações Finais}

Agora podemos processar o objetivo último deste texto, qual seja, a rearticulação entre cognição, lúdico e tecnologia. Nossa tradição filosófica manteve, consistentemente, a cognição separada dos processos lúdicos, das percepções e sensações, do mundo e, sobretudo, dos objetos técnicos.

Os processos de digitalização e integração de mídias característicos das TIC estimularam práticas lúdicas e de comunicação (exploração de ambientes, busca de informações, aprendizado de novas linguagens e softwares etc.) que requerem um refinamento em habilidades cognitivas. Com 0 advento das redes sociais, essas competências tornaram-se ainda mais potencializadas pelas possibilidades de interação social. Essas práticas são características presentes nas definições de jogos ao longo dos tempos e hoje são pressupostos básicos dos sistemas cognitivos. 0 entretenimento midiático atualmente é um pólo de convergência do lúdico, da tecnologia e da cognição, parecendo confirmar os pressupostos dos pedagogos franceses Jean Chateau (1987) e Gilles Brougère (1998) de que o jogo seria parte fundamental do desenvolvimento físico e cognitivo de todos os seres vivos.

Portanto, a verdadeira revolução dos sistemas de mídia e da indústria do entretenimento que observamos hoje se refere a processos em que são replicadas as formas de aprendizado e cognição que praticamos em nosso quotidiano.
Para tanto, contamos não apenas com processos de representação, mas com o corpo e suas sensorialidades, com a tecnologia, com 0 contexto e com as interações sociais. Se a cultura contemporânea replica a vida, parece-nos ser menos porque ela levaria sensacionalismo à política, à religião e a todos os campos da vida (GABLER, 1999), e mais porque utilizaria tarefas (interação social, exploração do ambiente etc.) características dos processos de cognição, aprendizagem e ludismo.

Henry Jenkins prevê o futuro do sistema de mídias da cibercultura:

Neste momento estamos usando esse poder coletivo principalmente para fins recreativos, mas em breve estaremos aplicando essas habilidades a propósitos mais "sérios". Neste livro, exploro como [...] a produção coletiva de significados, na cultura popular, está começando a mudar o comportamento das religiões, da educação, do direito, da política, da publicidade e mesmo do setor militar (JENKINS, 2008, p. 28).

\section{Referências}

AARSETH, Espen. Cybertext: perspectives on ergodic literature. Baltimore: The John Hopkins University Press, 1997.

ANDERSON, Chris. A cauda longa . Rio de Janeiro: Campus; Elsevier, 2006.

ARISTÓTELES. Política . Brasil: [344 a.C.?] Disponível em: <http://www.ateus.net/ebooks/index. php>. Acesso em: 02 mar. 2007.

BENJAMIN, Walter. A obra de arte na era de sua reprodutibilidade técnica. In: Obras Escolhidas: magia e técnica, arte e política: ensaios sobre a 
literatura e a história da cultura. 7 ed. São Paulo: Brasiliense, 1994. p. 165-196.

BODEN, Margareth. Introduction. In: The philosophy of artificial life. Oxford: Oxford University Press, 1996.

BROUGÈRE, Gilles. Jogo e educação. Porto Alegre: Artes Médicas, 1998.

CHATEAU, Jean. 0 jogo e a criança. São Paulo: Summus, 1987.

CLARK, Andy. Mindware: an introduction to the philosophy of cognitive science. New York: Oxford University Press, 2001.

DENNETT, Daniel. Kinds of minds. New York: Basic Books, 1996.

DESCARTES, René. Discurso do Método. São Paulo: Nova Cultural, 1996. (Coleção Pensadores).

DUFLO, Colas. 0 jogo: de Pascal a Schiller. Porto Alegre: Artes Médicas, 1999.

FELINTO, Erick. Videotrash: o Youtube e a cultura do "Spoof" na Internet. Galáxia, São Paulo, v. 16, p. 33-42, 2008.

GABLER, Neal. Vida, o filme: como o entretenimento conquistou a realidade. São Paulo: Companhia das Letras, 1999.

GEE, James Paul. What video games have to teach us about learning and literacy. New York: Palgrave Macmillan, 2007.

HUIZINGA, Johan. Homo ludens. 5.ed. São Paulo: Perspectiva, 2004.

JENKINS, Henry. Cultura da convergência. São Paulo: Aleph, 2008.

JOHNSON, Steven. Surpreendente! A televisão e o videogame nos tornam mais inteligentes. Rio de Janeiro: Elsevier, 2005.
KANT, Immanuel. Crítica da razão pura. Rio de Janeiro: Ediouro, [1781].

LAKOFF, George; JOHNSON, Mark. Philosophy in the flesh. Nova York: Basic Books, 1999.

LAUAND, L. Jean. Deus Ludens: o lúdico no pensamento de Tomás de Aquino e na pedagogia medieval. Brasil: Mandruvá, 2000. Disponível em: $<$ http://www.hottopos.com/notand7/jeanludus.htm>. Acesso em: 21 jan. 2008.

LEIBNIZ, G. W. New essays on human understanding. Reino Unido: s.n., 2006. Disponível em: <www. earlymoderntexts.com/pdf/leibne.pdf >. Acesso em: 19 jan. 2008.

LEMOS, André. Cibercultura: tecnologia e vida social na cultura contemporânea. Porto Alegre: Sulina, 2002.

LÉVY, Pierre, As tecnologias da inteligência. Rio de Janeiro: 34 Letras, 1993.

MANOVICH, Lev. Remixing and remixability, 2005. Disponível em: <http://www.manovich.net/DOCS/ Remix_modular.doc>. Acesso em: 25 jan. 2008.

MENZEL, Peter; D'ALUISIO, Faith. Robo Sapiens: evolution of a new species. Cambridge: MIT, 2000.

MORAVEC, Hans Paul. Mind children. Harvard University Press, 1988.

NORMAN, Donald. Things that make us smart. Cambridge: Perseus Books, 1993.

OLIVEIRA, Flávio Ismael da Silva; RODRIGUES, Sérgio Tosi. Affordances: a relação entre agente e ambiente. Ciências e Cognição, Niterói, v. 09, nov. 2006. Disponível em: http://www.cienciasecognicao. org/main/main09.html. Acesso em: 02 mar. 2007.

PLATÃO. A República. São Paulo: Nova Cultural, 1996. (Coleção Pensadores).

Fedro. Rio de Janeiro: Ediouro, [ca. 370 a.C.]. 
PORTO, Bruno. 'Tapa na Pantera' virou febre no Brasil e já ganhou até sequência. 0 Globo, Rio de Janeiro, 2006. Disponível em: <http://oglobo.globo. com/cultura/mat/2006/09/29/285891684.asp > . Acesso em: 26 out. 2010 .

REGIS, Fátima. Tecnologias de comunicação, entretenimento e competências cognitivas na cibercultura. Revista Famecos, Porto Alegre, n. 37, p. 32-37, 2008.

; PERANI, Letícia. Games, tecnologias de comunicação e capacitação cognitiva na cibercultura. In: SILVA, Augusto Soares da; MARTINS, José Cândido; MAGALHÃES, Luísa; GONÇALVES, Miguel (orgs.). Comunicação, Cognição, Media. Braga: Publicações da Faculdade de Filosofia - Universidade Católica Portuguesa, 2010. p. 491-502. Volume 1.

ROUSSEAU, Jean-Jacques. Emile. Estados Unidos: Project Gutemberg, 2004. Disponível em: < http://www. gutenberg.org/dirs/etext04/emile10.zip >. Acesso em: 21 jan. 2008.

SÁ, Simone Pereira de. Por uma genealogia da noção de materialidade da comunicação. In: CONGRESSO BRASILEIRO DE CIÊNCIAS DA COMUNICAÇÃO, 28., 2004, Porto Alegre. Anais... Porto Alegre: Intercom, 2004. CD-ROM. Quem media a cultura do shuffle? Cibercultura, Mídias e Cenas Musicais. Revista Famecos: mídia, cultura e tecnologia, Porto Alegre, n. 15, p. 05-11, jul. 2006.

SANTAELLA, Lúcia. Cultura e artes do pós-humano: da cultura das mídias à cibercultura. São Paulo: Paulus, 2003.

Navegar no ciberespaço: o perfil cognitivo do leitor imersivo. São Paulo: Paulus, 2004.

SIMMEL, Georg. A metrópole e a vida mental. In: VELHO, Otávio Guilherme (org.). 0 fenômeno urbano. Rio de Janeiro: Guanabara, 1987. p. 11-25.
SOARES, Letícia Perani. Interfaces gráficas e os seus elementos lúdicos: aproximações para um estudo comunicacional. 2008. Dissertação (Mestrado em Comunicação) - Faculdade de Comunicação Social/Programa de Pós-Graduação em Comunicação, Universidade do Rio de Janeiro, Rio de Janeiro, 2008.

VARELA, Francisco. Conhecer: as ciências cognitivas, tendências e perspectivas. Lisboa: Instituto Piaget, [1988 ou 1989]. 


\section{Communication and entertainment in cyberculture: rethinking the relations between ludic, cognition and technology}

\section{Abstract:}

The ICT have been engendering an authentic revolution in contemporary media and entertainment systems. This change enhances sociocultural practices - as participation, socialization and language learning - that incites the user to refine his or her cognitive abilities. This text aims to show how cyberculture, while highlighting the cognitive activities that exist in the practices of communication and contemporary entertainment, arouses a double reposition: the concepts game/entertainment and technology/media are both associated with cognition. We will base our assumptions in the change in the cognition concept effectuated during the 20th century to rethink the articulations between technology, ludic and cognition in cyberculture. Among the preliminary results, we can notice that entertainment ceases to be childish, unpretentious and escapist, coming near to the ludic category, and the technology ceases to be merely a device to become an agent in cognitive process.

\section{Keywords:}

Information and Communication Technologies. Cyberculture. Entertainment. Cognition.

\section{Comunicación y entretenimiento en la cibercultura: volviendo a pensar las articulaciones entre lúdico, cognición y tecnología}

\section{Resumen:}

Las Tecnologías de Información y Comunicación (TICs) han promovido una verdadera revolución en los sistemas mediáticos y de entretenimiento contemporáneos. Este cambio potencializa prácticas socioculturales - participación, sociabilización y aprendizaje de lenguajes que exigen del usuario un refinamiento de las habilidades cognitivas. El objetivo del presente texto es mostrar cómo en la cibercultura se evidencian las actividades cognitivas presentes en ciertas practicas de comunicación y de entretenimiento contemporáneas y cómo estas prácticas provocan un doble reposicionamiento: tanto en términos de la concepción de juego/ entretenimiento, cuanto en términos de las tecnologías/medias asociados a la cognición en si misma. Fundamentados en el cambio de la noción de cognición en el siglo XX proponemos reflexionar sobre las articulaciones entre tecnología, lo lúdico y cognición en el contexto de la cibercultura. Como resultados iniciales, se verifica 1) que el entretenimiento ya no puede ser considerado como algo infantil, no serio o escapista, sino algo que se aproxima de la categoría de lúdico; 2) que la tecnología deja de ser una simples herramienta para tornarse agente en los procesos cognitivos.

\section{Palabras clave:}

Tecnologias de Informação e Comunicação.

Cibercultura. Entretenimento. Cognição. 


\section{Expediente}

A revista E-Compós é a publicação científica em formato eletrônico da Associação Nacional dos Programas de Pós-Graduação em Comunicação (Compós). Lançada em 2004, tem como principal finalidade difundir a produção acadêmica de pesquisadores da área de Comunicação, inseridos em instituições do Brasil e do exterior.
E-COMPÓS I www.e-compos.org.br I E-ISSN 1808-2599

Revista da Associação Nacional dos Programas de Pós-Graduação em Comunicação. Brasília, v.13, n.2, maio/ago. 2010

A identificação das edições, a partir de 2008 passa a ser volume anual com três números.

\section{CONSELHO EDITORIAL}

Afonso Albuquerque

Universidade Federal Fluminense, Brasil

Alberto Carlos Augusto Klein

Universidade Estadual de Londrina, Brasi

Alex Fernando Teixeira Primo

Universidade Federal do Rio Grande do Sul, Brasil

Alfredo Vizeu

Universidade Federal de Pernambuco, Brasi

Ana Carolina Damboriarena Escosteguy

Pontifícia Universidade Católica do Rio Grande do Sul, Brasil

Ana Silvia Lopes Davi Médola

Universidade Estadual Paulista, Brasil

André Luiz Martins Lemos

Universidade Federal da Bahia, Brasil

Ângela Freire Prysthon

Universidade Federal de Pernambuco, Brasil

Antônio Fausto Neto

Universidade do Vale do Rio dos Sinos, Brasil

Antonio Carlos Hohlfeldt

Pontifícia Universidade Católica do Rio Grande do Sul, Brasil

Arlindo Ribeiro Machado

Universidade de São Paulo, Brasil

César Geraldo Guimarães

Universidade Federal de Minas Gerais, Brasil

Cristiane Freitas Gutfreind

Pontifícia Universidade Católica do Rio Grande do Sul, Brasil

Denilson Lopes

Universidade Federal do Rio de Janeiro, Brasil

Eduardo Peñuela Cañizal

Universidade Paulista, Brasi

Erick Felinto de Oliveira

Universidade do Estado do Rio de Janeiro, Brasil

Francisco Menezes Martins

Universidade Tuiuti do Paraná, Brasil

Gelson Santana

Universidade Anhembi/Morumbi, Brasil

Goiamérico Felício

Universidade Federal de Goiás, Brasil

Hector Ospina

Universidad de Manizales, Colômbia

Herom Vargas

Universidade Municipal de São Caetano do Sul, Brasil

leda Tucherman

Universidade Federal do Rio de Janeiro, Brasil

Itania Maria Mota Gomes

Universidade Federal da Bahia, Brasil

Janice Caiafa

Universidade Federal do Rio de Janeiro, Brasil

Jeder Silveira Janotti Junior

Universidade Federal da Bahia, Brasil

João Freire Filho

Universidade Federal do Rio de Janeiro, Brasil

John DH Downing

University of Texas at Austin, Estados Unidos

José Luiz Aidar Prado

Pontifícia Universidade Católica de São Paulo, Brasil

José Luiz Warren Jardim Gomes Braga

Universidade do Vale do Rio dos Sinos, Brasil

Juremir Machado da Silva

Pontifícia Universidade Católica do Rio Grande do Sul, Brasil

Lorraine Leu

University of Bristol, Grã-Bretanha

Luiz Claudio Martino

Universidade de Brasília, Brasil

Maria Immacolata Vassallo de Lopes

Universidade de São Paulo, Brasil

Maria Lucia Santaella

Pontifícia Universidade Católica de São Paulo, Brasil

Mauro Pereira Porto

Tulane University, Estados Unidos

Muniz Sodre de Araujo Cabral

Universidade Federal do Rio de Janeiro, Brasil

Nilda Aparecida Jacks

Universidade Federal do Rio Grande do Sul, Brasil

Paulo Roberto Gibaldi Vaz

Universidade Federal do Rio de Janeiro, Brasil

Renato Cordeiro Gomes

Pontifícia Universidade Católica do Rio de Janeiro, Brasil

Ronaldo George Helal

Universidade do Estado do Rio de Janeiro, Brasil

Rosana de Lima Soares

Universidade de São Paulo, Brasil

Rossana Reguillo

Instituto Tecnológico y de Estudios Superiores do Occidente, México

Rousiley Celi Moreira Maia

Universidade Federal de Minas Gerais, Brasil

Samuel Paiva

Universidade Federal de São Carlos, Brasil

Sebastião Albano

Universidade Federal do Rio Grande do Norte, Brasil

Sebastião Carlos de Morais Squirra

Universidade Metodista de São Paulo, Brasil

Simone Maria Andrade Pereira de Sá

Universidade Federal Fluminense, Brasil

Suzete Venturelli

Universidade de Brasília, Brasil

Valério Cruz Brittos

Universidade do Vale do Rio dos Sinos, Brasil

Veneza Mayora Ronsini

Universidade Federal de Santa Maria, Brasil

Vera Regina Veiga França

Universidade Federal de Minas Gerais, Brasi

COMISSÃO EDITORIAL

Felipe da Costa Trotta I Universidade Federal de Pernambuco, Brasi Rose Melo Rocha I Escola Superior de Propaganda e Marketing, Brasil Adriana Braga I Pontifícia Universidade Católica do Rio de Janeiro, Brasil

CONSULTORES AD HOC

Roseli Figaro I Universidade de São Paulo, Brasil

Miguel Serpa Pereira I Pontifícia Universidade Católica do Rio de Janeiro, Brasi João Maia I Universidade do Estado do Rio de Janeiro, Brasil Paulo Cunha Filho I Universidade Federal de Pernambuco, Brasi

Benjamim Picado I Universidade Federal Fluminense, Bras Josimey Silva I Universidade Federal do Rio Grande do Norte, Brasil

EDIÇÃO DE TEXTO E RESUMOS I Everton Cardoso

TRADUÇÕES PARA 0 INGLÊS I Lisa Earl Castillo e Sabrina Gledhil EDITORAÇ̃̃o ELETRÔNICA I Roka Estúdio
COMPOS I wWw.compos.org.br

Associação Nacional dos Programas de Pós-Graduação em Comunicação

Presidente

Itania Maria Mota Gomes

Universidade Federal da Bahia, Brasil

itania@ufba.br

Vice-presidente

Julio Pinto

Pontifícia Universidade Católica de Minas Gerais, Brasil juliopinto@pucminas.br

Secretária-Geral

Ana Carolina Escosteguy

Pontifícia Universidade Católica do Rio Grande do Sul, Brasil carolad@pucrs.br 